\title{
A influência da escolha musical para a caracterização da personagem Dulce Veiga
}

\author{
Mariana Kliemann Chagas
}

\begin{abstract}
Resumo: Este trabalho analisa três versões do datiloscrito do capítulo 7 do romance Onde andará Dulce Veiga? de Caio Fernando Abreu. Mais especificamente, analisar as diferentes opções do autor quanto à escolha de músicas para a composição da personagem Dulce Veiga e que influência tal escolha ocasiona para a sua caracterização. O trabalho faz parte do projeto de pesquisa "Arquivos literários e Memória cultural", orientado pela Prof ${ }^{\mathrm{a}} \mathrm{Dr}^{\mathrm{a}}$ Márcia Ivana de Lima e Silva. Sua relevância dentro da pesquisa mostra-se pela coleta, reunião e organização do conjunto da obra literária, poética, crítica, historiográfica, jornalística e de tradução de autoria de Caio Fernando Abreu, incluindo a produção dispersa, especialmente as publicações no Brasil e no exterior. Isto contribui para que se mantenha viva a memória desse escritor, e amplia o quadro literário e intelectual da literatura brasileira.
\end{abstract}

\begin{abstract}
This research aims at analyzing three versions of chapter 7 in the novel Onde andará Dulce Veiga? by Caio Fernando Abreu. More specifically, it attempts to review the different options made by the author regarding the selection of songs in order to compose the character Dulce Veiga, and also the influences such choices bring to this portrayal. The study is part of the research project named "Arquivos literários e Memória cultural" (literary files and cultural memory), which is led by $\mathrm{PhD}$. professor Márcia Ivana de Lima e Silva. Its relevance is proved by the collection, gathering, and organization of the literary, poetic, historiographical, and journalistic works, as well as the translations performed by Caio Fernando Abreu, including his scattered production published in Brazil and abroad. Thus, the project attempts to maintain the memory of this author and to broaden the literary and intellectual scope of Brazilian literature.
\end{abstract}

Keywords: Literature; Music; Genetic criticism

Analisar a gênese literária não é uma tarefa fácil, pois até mesmo para o próprio escritor, o processo de criação torna-se inconsciente. Visando entender um pouco mais as motivações que levam um escritor a desenvolver a sua obra, a Crítica Genética lança mão dos manuscritos para identificar as modificações da obra ao longo do processo de criação. $\mathrm{O}$ projeto de pesquisa "Arquivos literários e memória cultural", sob a orientação da Prof ${ }^{a} \operatorname{Dr}^{a}$ Márcia Ivana de Lima e Silva, com auxílio do Programa de Iniciação Científica da UFRGS (BIC/UFRGS), procura identificar este processo nos manuscritos pertencentes ao acervo de Guilhermino Cesar e Caio Fernando Abreu.

\footnotetext{
* Mariana Kliemann Chagas é licenciada em Letras pela Universidade Federal do Rio Grande do Sul (UFRGS). Participou do projeto de pesquisa "Arquivos Literários e Memória Cultural", sob a orientação da Profa. Dra. Márcia Ivana de Lima e Silva.
} 
Ao catalogar o acervo de Caio, foi possível encontrar três datiloscritos do capítulo 7 do romance Onde andará Dulce Veiga?, nos quais o narrador descreve o momento em que conheceu a personagem Dulce Veiga. Nessas versões, nota-se uma alteração significativa para o romance: o acréscimo de uma música que desempenha o papel de trilha sonora para a cena, sendo no total três músicas: "I left my heart in San Francisco", na versão de Dinah Washington, "Solitude" e "Crazy he calls me", ambas na gravação de Billie Holiday.

Nosso trabalho de pesquisa foi, primeiramente, encontrar as músicas e analisar suas letras para tentar identificar a motivação do autor para fazer tais rasuras. Procuramos também a história das cantoras, suas características e o histórico das músicas. Então, buscamos nas cartas pessoais de Caio Fernando Abreu seus comentários sobre o processo de criação do livro e suas idéias para a personagem. Após essa pesquisa, tentamos descobrir as intenções presentes nestes datiloscritos específicos.

O motivo para o acréscimo de uma música na cena parece-nos bem claro, uma vez que a personagem é uma cantora e a música faz parte constante de sua vida. Nas palavras do próprio Caio, em carta destinada a Luciano Alabarse: "Dulce Veiga é um livro todo construído no sentido do encontro com o ato de CANTAR. Que se possa cantar e o universo passa a ter sentido" (MORICONI, 2002). Ou seja, o acréscimo se torna justificável considerando a própria temática da obra. Sem este acréscimo, a personagem tornar-se-ia incoerente, pois, antes de saber cantar, é necessário saber apreciar a música. Assim como um escritor precisa ser, antes de mais nada, um bom leitor.

Mas, em contrapartida, quais seriam as motivações de Caio para alterar a música desta cena? A cada datiloscrito, Caio altera a música, sendo que no primeiro datiloscrito a música é "I left my heart in San Francisco", na versão de Dinah Washington. Caio imaginava Dulce Veiga como uma cantora de voz rouca, "que só bebe Strega e tem por volta dos 50/55 anos" (MORICONI, 2002). Essas características se encaixariam com o perfil de Dinah Washington, considerada a rainha do blues. Mas se as impressões estão colocadas, por que Caio decide trocar a música e a cantora?

É notória a designação gay que San Francisco clama, intencionalmente. Esta cidade reivindica o título de cidade dos homossexuais por ter o primeiro prefeito assumidamente gay. Com isso, a música "I left my heart in San Francisco" ficou conhecida como hino do orgulho gay. Também é notória a critica redutora relativa à obra de Caio Fernando, que sempre foi rotulada como "literatura gay", e que este seria seu único mérito, não fazendo parte da "grande literatura", assim como a de Clarice Lispector é considerada uma "literatura feminina", designação igualmente redutora e que Clarice abominava. 
Uma das intenções de Caio ao fazer a alteração da música pode ser desvencilhar a obra deste "rótulo" gay. Onde andará Dulce Veiga? é uma inovação na prosa de Caio, uma vez que ele incorpora o gênero policial. Logo, com o intuito de que a obra não seja lida sob tal rótulo, Caio altera a música para que o romance não seja estigmatizado. Como o próprio Caio diz, em carta destinada a Maria Lídia Magliani "Descobri o fascínio do enredo, das personagens - ficção mesmo" (MORICONI, 2002). Também em carta a José Márcio Penido, Caio reforça a singularidade do romance: “[...] sinto que é como se fosse meu primeiro livro, no sentido de que me desembaracei do umbigo e cheguei mais perto da ficção, do Brasil, do humano alheio, não apenas meu" (MORICONI, 2002). Ou seja, essa não é uma obra como as outras, portanto, não deve ser lida como as outras e muito menos ser relacionada às escolhas sexuais de Caio. Ele propõe que este romance retrate o outro e que a crítica consiga enxergar que o seu universo é muito mais complexo do que apenas a temática homossexual.

Então, Caio Fernando vê a necessidade de encontrar uma música que preserve as características da personagem sem que o livro se torne rotulável. Para isso, propõe que a nova trilha seja "Solitude", na voz de Billie Holiday. A característica de Billie presente em Dulce Veiga é a mais importante de todas: a vontade de cantar. Ao fazer a troca da cantora, Caio percebe que esta era a característica a ser realçada e que esta escolha seria definitiva (Billie Holiday mantém-se como escolha para ser a intérprete da "música-trilha" na versão final).

O que gera a diferença é a letra da música em si. "Solitude" descreve uma mulher em plena solidão, sentada em sua cadeira, experimentando a tristeza. É exatamente a mesma descrição que o narrador faz de seu encontro com Dulce Veiga, também em sua cadeira. Na música, o eu lírico prevê que ficará louca em breve, tudo por causa do amor. No caso de Dulce, seu amor é pela arte de cantar. Caio encontra a música perfeita para 'embalar' a cena, pois parece ter sido composta especialmente para o livro.

Mesmo assim, Caio Fernando se mostra insatisfeito e decide fazer uma nova troca no $3^{\circ}$ datiloscrito. Caio substitui "Solitude" por "Crazy he calls me", ainda na voz de Billie Holiday. O que teria motivado esta troca, uma vez que a segunda opção parece ter se encaixado tão perfeitamente na cena?

"Crazy he calls me" retrata uma mulher que declara seu amor desmedido, dizendo que faria tudo, "mover montanhas", "atravessar o fogo", ou o que mais fosse necessário. Por esse motivo, é considerada "louca". Esta música retrata muito mais a personalidade de Dulce do que a cena em si. Assim como o eu lírico, Dulce abandona tudo, literalmente tudo, para se dedicar exclusivamente ao seu amor, a arte de cantar. Fazendo essa troca, Caio não quer mais retratar a cena, o encontro, mas sim caracterizar a personalidade da personagem, que é capaz 
de tudo por amor. Desta forma, Caio antecipa o final da trama, explicando o motivo pelo sumiço de Dulce Veiga. Mas essa pista só será identificada pelo leitor que conhece a música ou que for atrás deste detalhe.

Agora, a música se torna não mais um elemento que deveria ser adicionado pela necessidade de retratar a temática do livro, o ato de cantar, mas sim um elemento indispensável para a nova proposta de Caio no gênero policial. A música se torna uma pista da trama.

Este romance foi escrito ao longo de cinco anos, sendo que a proposta original era de um conto e não um romance. Segundo Caio F., "foram umas 2 mil páginas para tirar pouco mais de 200" (MORICONI, 2002). Ele mesmo revela que cada palavra foi pensada. "Foi escrito gota-a-gota, palavra-por-palavra" (MORICONI, 2002). Nada mais natural do que o autor modificar várias vezes suas versões.

Infelizmente, o acervo não detém todos os datiloscritos deste romance, nem mesmo todas as versões para esta cena específica, o que impossibilita que a pesquisa seja mais aprofundada. Acreditamos na existência de mais algumas versões para esta cena pelo fato de a versão final (impressa) ter mais acréscimos do que os encontrados no terceiro datiloscrito. Com certeza, o acesso a todos os datiloscritos deste romance permitir-nos-ia realizar um estudo detalhado do processo de criação de Caio Fernando Abreu, pois seriam visíveis todas as suas intenções ao realizar uma alteração. Desta maneira, a pesquisa pode valorizar o tratamento que Caio dá à linguagem e, conseqüentemente, difundir este autor que propõe questões muito mais complexas do que as comumente apresentadas pela crítica.

\section{Referências}

ABREU, Caio Fernando. Onde andará Dulce Veiga? São Paulo: Planeta de Agostini, 2003. MORICONI, Ítalo (Org). Caio Fernando Abreu Cartas. Rio de Janeiro: Aeroplano, 2002.

\section{Anexos:}




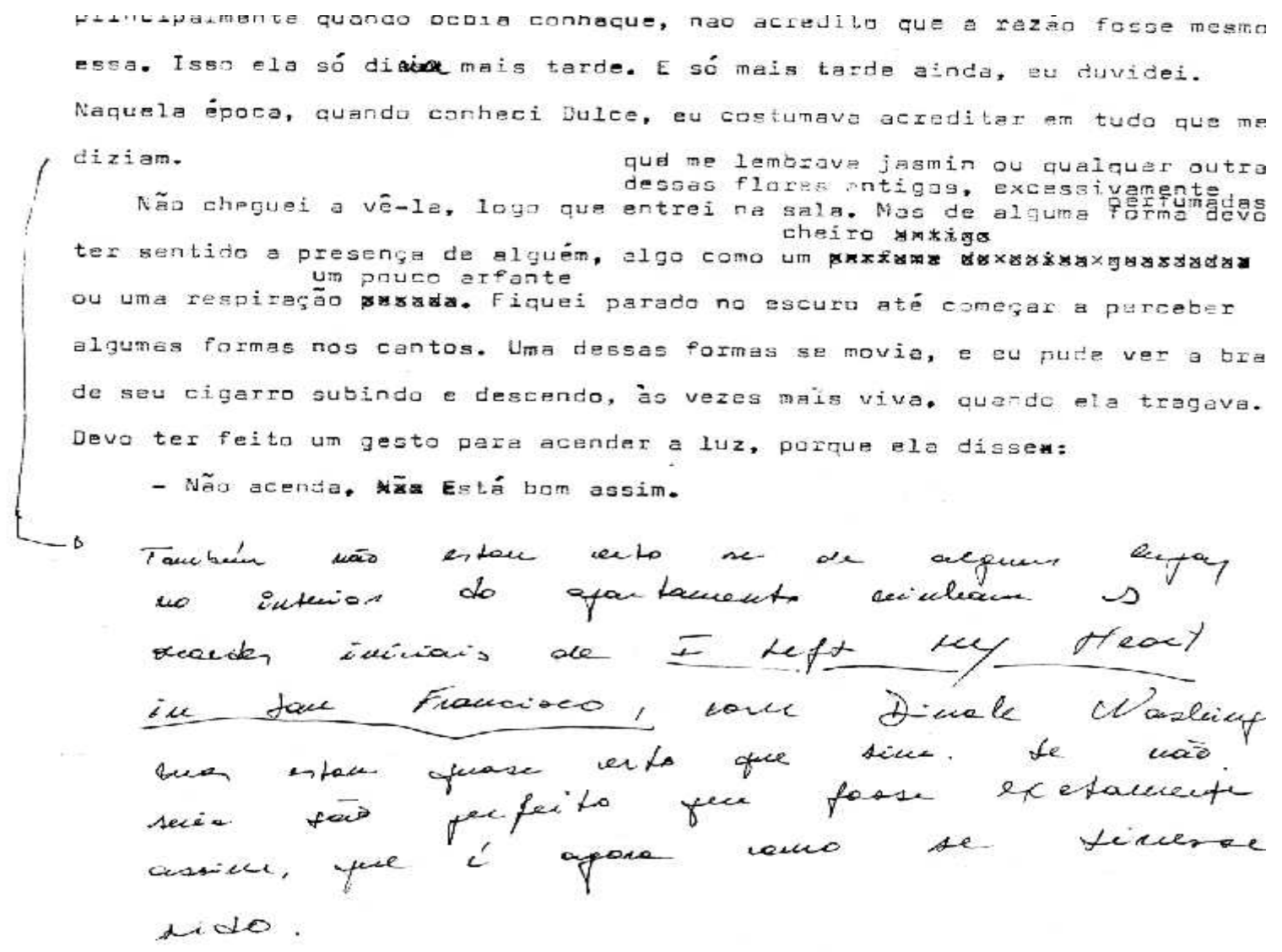

\section{I left my hart in San Francisco}

Frank Sinatra

I left my heart

In San Francisco

High on the hill

It calls to me.

To be where little cables cars

Climb halfaway to the stars!

The morning fog may chill the air.

I don't care!

My love waits there in San Francisco

Above the blue and windy sea.

When I come home to you 
San Francisco

Your golden sun will shine for me!

I left my heart

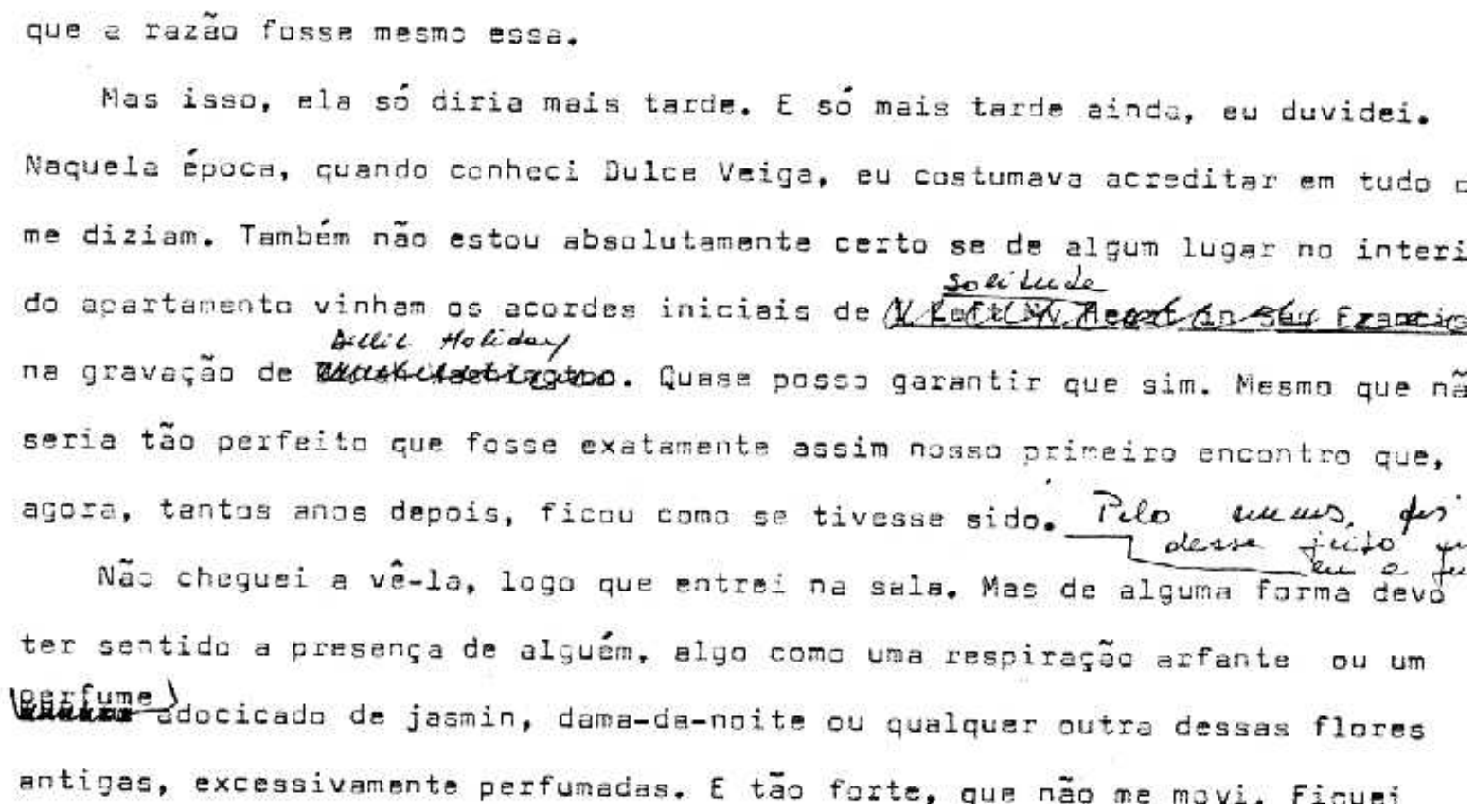

\section{Solitude}

In my solitude you haunt me

Billie Holiday/Louis Armstrong

With reveries of days gone by

In my solitude you taunt me

With memories that never die

I sit in my chair

Filled with despair

Nobody could be so sad

With gloom ev'rywhere

I sit and I stare

I know that I'll soon go mad

In my solitude

I'm praying

Dear Lord above

Send back my love 


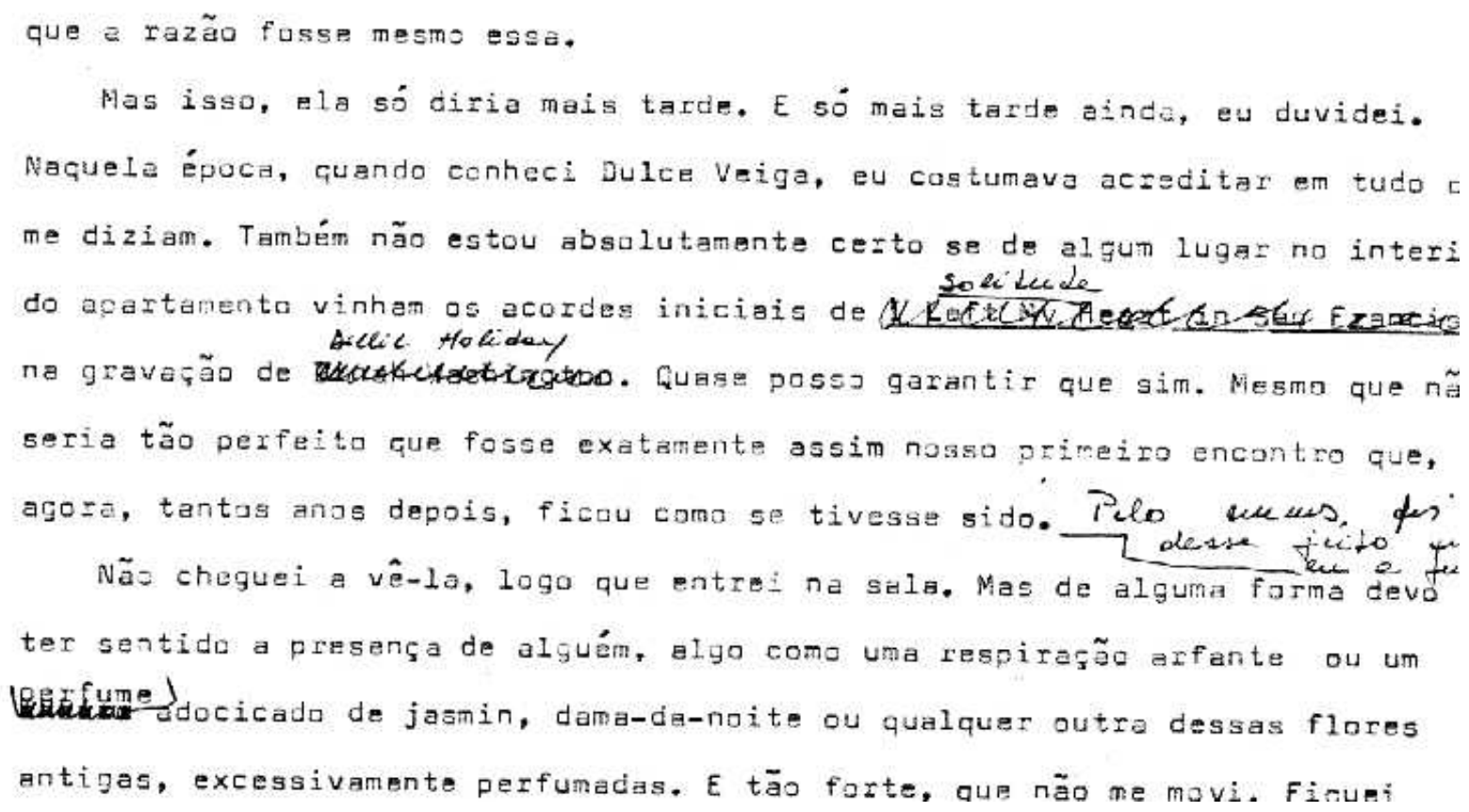

\section{Crazy, he calls me}

Carl Sigman / Bob Russell

I say I'll move the mountains

And I'll move the mountains

If he wants them out of the way

Crazy he calls me

Sure, I'm crazy

Crazy in love, I say

I say I'll go through fire

And I'll go through fire

As he wants it, so it will be

Crazy he calls me

Sure, I'm crazy

Crazy in love, you see

Like the wind that shakes the bough

He moves me with a smile

The difficult I'll do right now 
The impossible will take a little while

I say I'll care forever

And I mean forever

If I have to hold up the sky

Crazy he calls me

Sure, I'm crazy 